\title{
Cost Analysis Methodology Photovoltaic Manufacturing Technology Project
}

\section{Annual Subcontract Report 11 March 1991 - 11 November 1991}

Richard A. Whisnant

Research Triangle Institute

Research Triangle Park, North Carolina

NREL technical monitor: R.L. Mitchell

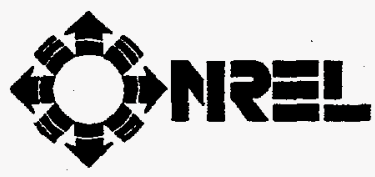

National Renewable Energy Laboratory 1617 Cole Boulevard

Golden, Colorado 80401-3393

A Division of Midwest Research Institute Operated for the U.S. Department of Energy under Contract No. DE-AC02-83CH10093

Prepared under Subcontract No. XR-1-11039-1

September 1992 


\title{
On September 16, 1991 the Solar Energy Institute was designated a national laboratory, and its name was changed to the National Renewable Energy Laboratory.
}

\section{NOTICE}

This report was prepared as an account of work sponsored by an agency of the United States government. Neither the United States government nor any agency thereof, nor any of their employees, makes any warranty, express or implied, or assumes any legal liability or responsibility for the accuracy, completeness, or usefulness of any information, apparatus, product, or process disclosed, or represents that its use would not infringe privately owned rights. Reference herein to any specific commercial product, process, or service by trade name, trademark, manufacturer, or otherwise does not necessarily constitute or imply its endorsement, recommendation, or favoring by the United States government or any agency thereof. The views and opinions of authors expressed herein do not necessarily state or reflect those of the United States government or any agency thereof.

\author{
Printed in the United States of America \\ Available from: \\ National Technical Information Service \\ U.S. Department of Commerce \\ 5285 Port Royal Road \\ Springfield, VA 22161
}

Price: Microfiche A01

Printed Copy $\mathrm{A03}$

Codes are used for pricing all publications. The code is determined by the number of pages in the publication. Information pertaining to the pricing codes can be found in the current issue of the following publications which are generally available in most libraries: Energy Research Abstracts (ERA); Government Reports Announcements and Index (GRA and I); Scientific and Technical Abstract Reports (STAR); and publication NTIS-PR-360 available from NTIS at the above address. 


\section{DISCLAIMER}

Portions of this document may be illegible electronic image products. Images are produced from the best available original document. 


\section{TABLE OF CONTENTS}

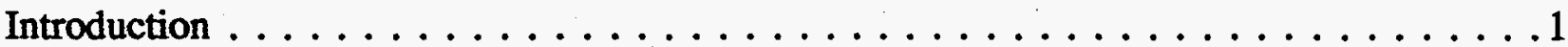

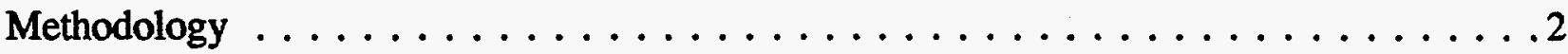

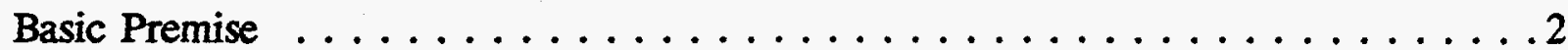

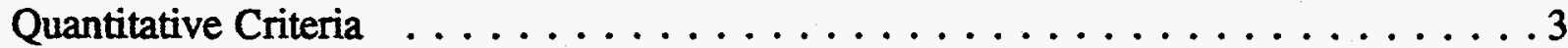

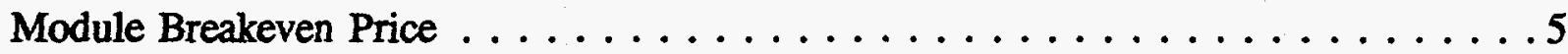

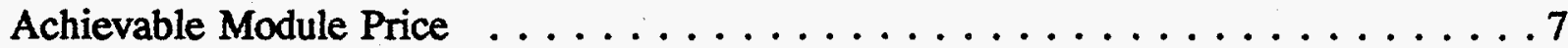

Model Framework $\ldots \ldots \ldots \ldots \ldots \ldots \ldots \ldots \ldots \ldots \ldots \ldots$

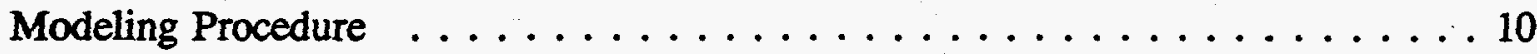

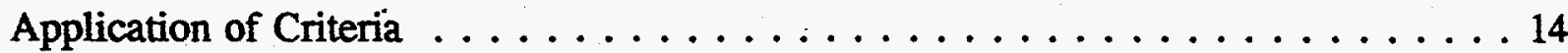

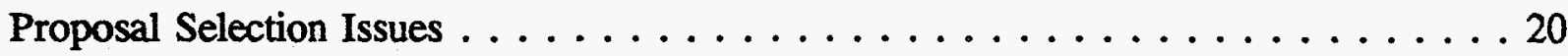




\section{LIST OF FIGURES}

Figure 1. Corporate Organizational Structure $\ldots \ldots \ldots \ldots \ldots \ldots$

Figure 2. Production Flow Features $\ldots \ldots \ldots \ldots \ldots \ldots \ldots$

Figure 3. Work Station Data Definition . . . . . . . . . . . . . . 10

Figure 4. STAMPP Modeling Overview $\ldots \ldots \ldots \ldots \ldots \ldots \ldots \ldots \ldots \ldots$

Figure 5. Example PV Cost Analysis Criteria Application . . . . . . . . . 15 


\title{
Photovoltaic Manufacturing Technology Project
}

\author{
Cost Analysis Methodology
}

\section{INTRODUCTION}

The Solar Energy Research Institute (SERI) has initiated a five-year project to support the translation of research and development in photovoltaic (PV) technology into the marketplace. The Photovoltaic Manufacturing Technology Project (PVMaT), conceived as a Department of Energy/industry partnership, seeks to advance PV manufacturing technologies, reduce PV module production costs, increase module performance, and expand U.S. commercial production capacities.

Under the PVMaT project, manufacturers will propose specific manufacturing process improvements that may contribute to the goals of the project. At the present time there are numerous physical realizations of PV technology commercially available and others still in development. PV system technology can be divided into concentrator and flat plate systems, each having preferred applicability in different climatic regions and for different end-uses. The physical designs for the two divisions and the manufacturing processes that define their costs are very different. Within each of the two basic divisions are a variety of cell technologies based on different semiconductor materials systems, each having its own manufacturing process with its inherent characteristics. While great progress has been made in PV technology in the past 15 years, product costs limit its application to small scale applications, generally for remote sites. The PVMaT project can hasten entry into the larger scale, grid-connected applications.

The PVMaT project has two phases: Phase 1, to identify obstacles and problems associated with manufacturing processes; and Phase $2 \mathrm{~A}$, to address the problems identified in Phase 1 and other issues related to achieving the project goals. The PVMaT project anticipated that these obstacles might include, for example, process rates, process control, encapsulation, yield, throughput, scaling to larger areas, material utilization efficiency, substitution of more cost effective materials, and introduction or increased use of automation and robotics. During Phase 1, the participants will complete detailed descriptions of:

a. the overall procedure involved in the manufacture of modules and/or cells;

b. the potential module and/or cell manufacturing process (or changes) that can lead to improved performance, reduced manufacturing costs, and significantly increased production; and long range potential benefits of the improved process;

c. the problems that impede the achievement of the potential benefits in $b$, including generic problems; 
d. approaches to the solutions of the problems identified in c., including estimates of the cost and time for achieving those solutions.

During Phase 1, directed RFPs will be issued to the recipients to which they may respond with proposals for support under Phase $2 \mathrm{~A}$. These proposals are expected to contain information based on the effort in Phase 1 that will allow them to be evaluated and ranked for selection. The evaluation is to be based on a number of factors, including:

a. the current manufacturing capability of the offerer,

b. the potential manufacturing capability of the offerer's technology,

c. the likelihood that the problems impeding the future cost reductions will be solved,

d. the viability of the proposed technical plan for reducing production costs and increasing production capacity,

e. the total cost in achieving the stated objectives and the cost effectiveness of the proposal.

Twenty-two firms have been funded under Phase 1 of the PVMaT project, and they do indeed represent a wide range of PV technology. In order to provide, to the greatest extent possible, a fair and impartial evaluation of Phase $2 \mathrm{~A}$ proposals, a methodology for comparing PV manufacturing processes has been defined. The methodology is constructed in such a way that, given adequate definition of the input data, quantitative assessments can be made that address the evaluation factors given above for Phase 2A.

\section{METHODOLOGY}

\section{Basic Premise}

Emphasis in the PVMaT project is on the improvement in manufacturing processes in order to reduce product cost and make the PV module competitive in a broader energy supply market. The question is how to rank, preferably quantitatively, the Phase $2 \mathrm{~A}$ proposals for manufacturing process improvements. A yardstick is needed. The linkage between module cost and manufacturing process cost factors, such as labor, materials, equipment and operational factors is clear and can be modeled. The linkage between allowable PV module cost and the cost of electricity in grid-connected market applications has been explored extensively and can also be modeled. Experiments have shown that PV systems can reliably supply a considerable portion of a utility's daily peak load if the PV system cost is low enough. Therefore, a yardstick based on electricity supply in the grid is a reasonable one. A basic premise of the PV Cost Analysis Methodology is that the relative value of process improvements proposed for Phase 2A is in proportion to their potential for bringing module prices to the point where the electric 
energy produced is competitive with electricity from the grid. There are certainly intermediate markets that are important to the evolution of the PV industry, but the utility grid market provides a useful yardstick for ranking in the PVMaT program. Evaluation of proposals can be more objective if a method can be employed that quantitatively relates the proposed process improvements to the module cost in a fair and uniform manner. This PV Cost Analysis Methodology is intended to provide the means for such evaluation.

The PV Cost Analysis Methodology has three basic elements:

1. Criteria for ranking the Phase 2A proposals in order of those most likely to enhance the market penetration of photovoltaic power generation.

2. Characterization Parameters to characterize the proposed processes in such a manner that the criteria can be quantified, or at least contribute to qualitative judgments of the criteria.

3. A procedure for ranking the Phase $2 \mathrm{~A}$ proposals using the criteria.

It is important to define both the criteria and the characterization parameters in such a manner that they are mutually compatible and supportive of the overall methodology. This requires a computation methodology to utilize the parameters and either calculate the criteria directly, or calculate quantities from which the criteria can be determined. In the following section, the quantitative criteria are defined, followed by a definition of two computational procedures to establish a required set of characterization parameters. The application of the criteria in a ranking procedure is then discussed.

\section{Quantitative Criteria}

In the Introduction, the notion was introduced of evaluating Phase 2A proposals in light of their contribution to reducing PV module prices to allow them to compete in grid connected electricity markets. The largest potential market for PV generation is utility-owned generation. There may well be a number of other markets for PV capacity. However, a benchmark of utility-owned generation is very useful for examining the potential of PV manufacturing process improvements and comparing their relative merits. As defined later, such a benchmark can be clearly defined in quantitative terms. The comparison is based on the notion that the manufacturing process improvements resulting from the PVMaT project will result in products that come closer to meeting, or exceeding by some amount, the breakeven product price established for utility-owned systems and the modules within those systems. The product that comes closest to meeting, or exceeds by the largest amount, the breakeven price would rank highest, all other criteria being equal. Of course, the ranking must be done on proposed process improvements, and the likelihood that the proposed process improvements will be achieved, as well as the likelihood that if they are achieved the projected product price will also be achieved, must also be assessed. Factors that impact those likelihoods are addressed by the PVMaT 
project evaluation factors, which are restated here in terms that can be translated to the PV Cost Analysis Methodology .

the current (actual or projected) module price in relation to the breakeven price (i.e., how far does the technology have to go, pricewise?)

the current technical status of the product and process (i.e., how far does the product/process have to go as measured, for example, by module efficiency, process yield or throughput?)

the amount of funding that is proposed to accomplish the process improvement in relation to the price reduction necessary (i.e., is the funding likely to be adequate to achieve the proposed result?)

the nature of the process and the proposed improvements (i.e., what is proposed technically and is it likely that the physics and engineering factors involved will yield the proposed improvements?)

the qualifications and experience of the people proposed to carry out the proposed development program (i.e., do they have technical qualifications and experience likely to contribute to the program success?)

the financial commitment of the proposer to both the funded effort and the PV business (i.e., is the commitment of the proposer reflected in past and present involvement in the PV business, what proportion of the cost of the proposed effort will be privately provided, and what evidence is there of potential for supplying products to the market in the future?)

There is obviously a considerable amount of qualitative judgement to be applied in evaluating these points in relation to a given Phase $2 \mathrm{~A}$ proposal, but there is also some quantitative information that can be developed given sufficient detail in the proposal responses. The objective is to relate proposed manufacturing process improvements to the progress toward breakeven module price goals, which can be established from competitive electricity prices and assumptions on balance-of-system costs and insolation. Ideally, the impact of specific process improvements on product price can be elucidated. Quantitative comparison of proposed manufacturing process improvements among diverse processes could then be made. Computational methods are available to provide both a breakeven module price and to relate manufacturing process parameters to required module selling prices. These will be discussed following the statement of evaluation criteria.

Any PV manufactiring process produces a module that can be characterized by its overall area, its peak power output under specified insolation input (i.e., its efficiency) and by its price to the buyer. Other more detailed specifications include voltage and current at peak output, fill factor, and, of particular importance for a-Si thin film modules, the long-term stability of the 
output. For the purposes ranking in this methodology, the two key parameters that characterize the module are the module price in $\$ / \mathrm{m}^{2}$ and the achieved stable module conversion efficiency. The module manufacturing process, along with product design, determines price in $\$ / \mathrm{m}^{2}$. Price is determined by the consumption of materials, and equipment cost, throughput and yield. A process has a throughput expressed in the number of modules produced of a given size in a time period (e.g., a year) that is a function of the design of the module, the process capabilities of the equipment, the process operations performed, and the skill of people in operating that equipment. Processes with high throughput per dollar invested produce products of lower price. Efficiency is a function of both product design and processing proficiency. The efficiency of the modules produced normally is distributed about some mean value, and the mean and standard deviation are resultant process characteristics that are important in comparing and ranking processes. The higher the mean and the smaller the standard deviation, the better the process. These statistics may be difficult to ascertain, especially for processes with little history of production, and they can only be estimated for the proposed improved processes. The standard deviation is therefore perhaps of secondary concern unless it is apparent that certain processes inherently result, for example, in much wider standard deviations than others.

Based on the preceding considerations, a set of quantitative criteria is defined as:

-current price status of the module $\left(\$ / \mathrm{m}^{2}\right)$, actual or computed

-current module efficiency, mean and standard deviation

-projected module price under defined design and process assumptions

-projected module efficiency consistent with the pricing assumptions, mean and standard deviation

-breakeven price for a selected market as a function of system efficiency

\section{Module Breakeven Price}

Utility scale breakeven prices for PV systems can be defined using a method originated by the Electric Power Research Institute (EPRI)'. The cost relationships associated with this method are the basis for parametric relationships from which the allowable module price for a given application scenario (location, competing cost of utility generated electricity, balance-ofsystem costs, and other financial parameters) can be determined. This allowable module price is the breakeven price for the market represented by the scenario, and can be used to evaluate the Phase 2A proposals.

The equations that define this method of determining breakeven cost are given below, and they define the parameters that determine the breakeven module price. Some of these variables will become part of the characterization parameters. They do not characterize the manufacturing processes, but they do establish the gauge against which the potential of the processes can be ranked. 
The cost of electric energy produced by a PV installation with an area sufficient to produce $1 \mathrm{kWac}$ at the bus bar under Nominal Peak Operating Conditions can be stated as:

$$
\text { EnergyCost }=\text { AreaCos } t+\text { PowerCos } t+\text { OMCost }
$$

The energy cost can be more explicitly stated as:

$$
E C=\frac{L C C}{(8760)(C F)}[I N D C][(A)(M A C+B A C)+B P C]+(A)(L) \frac{O M}{(8760)(C F)}
$$

where

$$
\begin{aligned}
& \mathrm{EC}=\text { Levelized energy cost, } \$ / \mathrm{kWh} \\
& \text { LCC }=\text { Fixed charge rate, fraction } \\
& \mathrm{CF}=\text { Plant capacity factor, based on nominal peak operating conditions and site } \\
& \text { annual insolation, fraction } \\
& \text { INDC }=\text { Indirect cost multiplier, accounts for costs of erecting PV plant not } \\
& \text { included in } \mathrm{EC},>1.0 \\
& \text { A }=\text { PV plant aperture area required to generate } 1 \mathrm{kWac} \text { at the bus bar under } \\
& \text { nominal peak operating conditions, } \mathrm{m}^{2} \\
& \text { MAC }=\text { Module price delivered to site, } \$ / \mathrm{m}^{2} \\
& \text { BAC }=\text { Balance-of-system area related costs, } \$ / \mathrm{m}^{2} \\
& \mathrm{BPC}=\text { Balance-of-system power related costs, } \$ / \mathrm{kW} \\
& \mathrm{L}=\text { Levelizing factor for recurring } 0 \& \mathrm{M} \text { costs, }>1.0 \\
& \mathrm{OM}=\text { Annual O\&M costs, } \$ /\left(\mathrm{m}^{2} \text {-year }\right)
\end{aligned}
$$

The plant aperture area, $A$, is related to the insolation, $I_{p}$, and the system efficiency, $\eta_{3}$, by:

$$
A=\frac{1}{\left(I_{p}\right)\left(\eta_{s}\right)}
$$

By substituting this expression into the one for energy cost and solving for allowable module cost, the following expression relating the module cost to other PV generation plant parameters is obtained:

$$
M A C=\frac{(8760)(C F)(E C)\left(I_{p}\right)\left(\eta_{s}\right)}{(L C C)(I N D C)}-B A C-(B P C)\left(I_{p}\right)\left(\eta_{s}\right)-\frac{(L)(O M)}{(L C C)(I N D C)}
$$

The preceding equations cover either flat plate or concentrator PV systems. However, while plant aperture area and cell area are nearly the same for flat plate systems, they are quite different for concentrator systems. Concentrator systems tradeoff a reduction in cell area that is inversely proportional to the concentration ratio with the attendant reduction in the contribution of cell cost to module cost against increased costs of the module structure, supporting/tracking structure and tracking drive. The insolation for the concentrating system is also reduced, but efficiency is potentially higher. These differences are taken into account 
in the relationships above for allowable module cost by appropriate differences in the parameters.

In using the above relationships in the PV Cost Analysis Methodology, the procedure is to select values for all parameters except the efficiency and to calculate the breakeven module area-related price as a function of efficiency. The efficiency in the above equations is the system efficiency, and this would have to be related to the module or receiver efficiency by considering optical and electrical losses in the system. The use of the breakeven price versus efficiency relation in ranking is discussed subsequently in the Application of Criteria section.

\section{Achievable Module Price}

The tool to be used in determining the module price achievable with a proposed process is a program called STAMPP (STrategic Analysis of Manufacturing Process and Price) that has been evolved by the Research Triangle Institute over several years. STAMPP has been used to study the manufacturing process for both photovoltaic cells/modules and integrated circuits. A general description of the STAMPP program is provided here to illustrate its cost analysis capability and provide the basis for defining the Characterization Parameters and its applicability to the Phase 2A proposal evaluation process. STAMPP can also be used to calculate achievable prices for current processes that have no established market price or to provide a sanity check on claimed current achievable prices.

STAMPP models the manufacturing operations of a firm and its overhead and financial structure to calculate a required price of the product produced. It is based on a required revenue (sales) methodology to determine price. The product price provides a specified rate of return on equity investment at a specified annual level of production. Among the outputs of the model are a corporate income statement and balance sheet that allows an assessment of the modeled business in terms of financial and business criteria. These reports are based on accepted accounting procedures. On the manufacturing side, reports are provided that summarize the equipment, labor, materials, floor space, and utilities required in terms of both quantity and cost. Also reported are personnel and associated costs for administrative functions. The result is a complete picture of all aspects of the cost structure underlying the required product price. The STAMPP model provides the capability to identify the impact on required price of changes in the manufacturing process if those changes can be defined in terms of STAMPP input data as defined subsequently.

\section{Model Framework}

The objective of the STAMPP approach is to model at a specified level of detail all of the costs associated with manufacturing a product by a firm or profit center, to determine the price the firm must charge to operate a profitable business, and to provide sufficient detail on costs that, in the case of the PVMaT project, the impact on price of process and/or product changes can be quantified. STAMPP models the physical manufacturing operations, the 
personnel organization of the firm and the physical facilities that houses these operations and people in order to capture the full cost of producing a product.

STAMPP allows the modeling of a hypothetical organization shown in Figure 1 that covers most, if not all, of the functions necessary to operate a firm. The top level positions in the organization are assumed to be filled. The number of employees in the manufacturing area who operate machines or perform maintenance, materials handling or quality control duties are determined from the simulation of the manufacturing operations (described subsequently). Foremen and area supervisors are determined based on the number of these employees directly associated with production. The support staffing in the administrative areas is a function of the total employment of the firm. Thus, the employment has a fixed base level of management people, and the total employment is a function of the employment in the manufacturing area, which, in turn, is a function of the production volume and the manning specified for each production machine.

The physical operations of manufacturing are modeled in STAMPP as illustrated by Figure 2. In order to define the product manufacturing operations flow, STAMPP uses a block called the "work station". A work station is defined as a collection of identical machines (one or more), each performing the same operations in parallel. The user specifies the interconnection of the work stations. An arbitrary path ending at the output of the final product is designated the "trunk" sequence. "Branch" sequences of work stations are allowed to model subassemblies or component fabrication. The model also allows rework of partially completed product, either with or without additional work stations in the rework sequence. Sampling of the work station output for inspection is also allowed, with reinsertion of product when inspection is nondestructive or scrapping of inspected product when the testing is destructive. For the purpose of aggregating cost data developed by the model, work stations may be assigned to cost centers.

The operations performed at a work station are defined by the user on a per-machine basis. The work station may have more than one machine and the number of machines for each work station is determined by the model based on a specified annual volume of the final product and the specified individual machine parameters. The work station is characterized by the nominal operating parameters of one of its machines. Those parameters are illustrated in Figure 3 , and are defined as long-term average values. The production rate defines the nominal or design value in units of intermediate or final product (for the last trunk station) output per unit time when the machine is running. Use rates for materials, labor and utilities can be specified on a per-unit-time or per-unit-product basis. The calculated quantities shown in Figure 3 are all at the work station level. The product data flow values are calculated by the model using steady-state product/materials balance procedure that begins with the final product volume specified and moves backwards along the trunk process, taking into account the yield, rework, inspection and branch flow parameters to determine the product input to each work station and the materials, labor facilities and utilities requirement quantities at each station. The same type of product/materials balance is then carried out along each of the branch processes.

PV Cost Analysis Methodology

Research Triangle Institute 


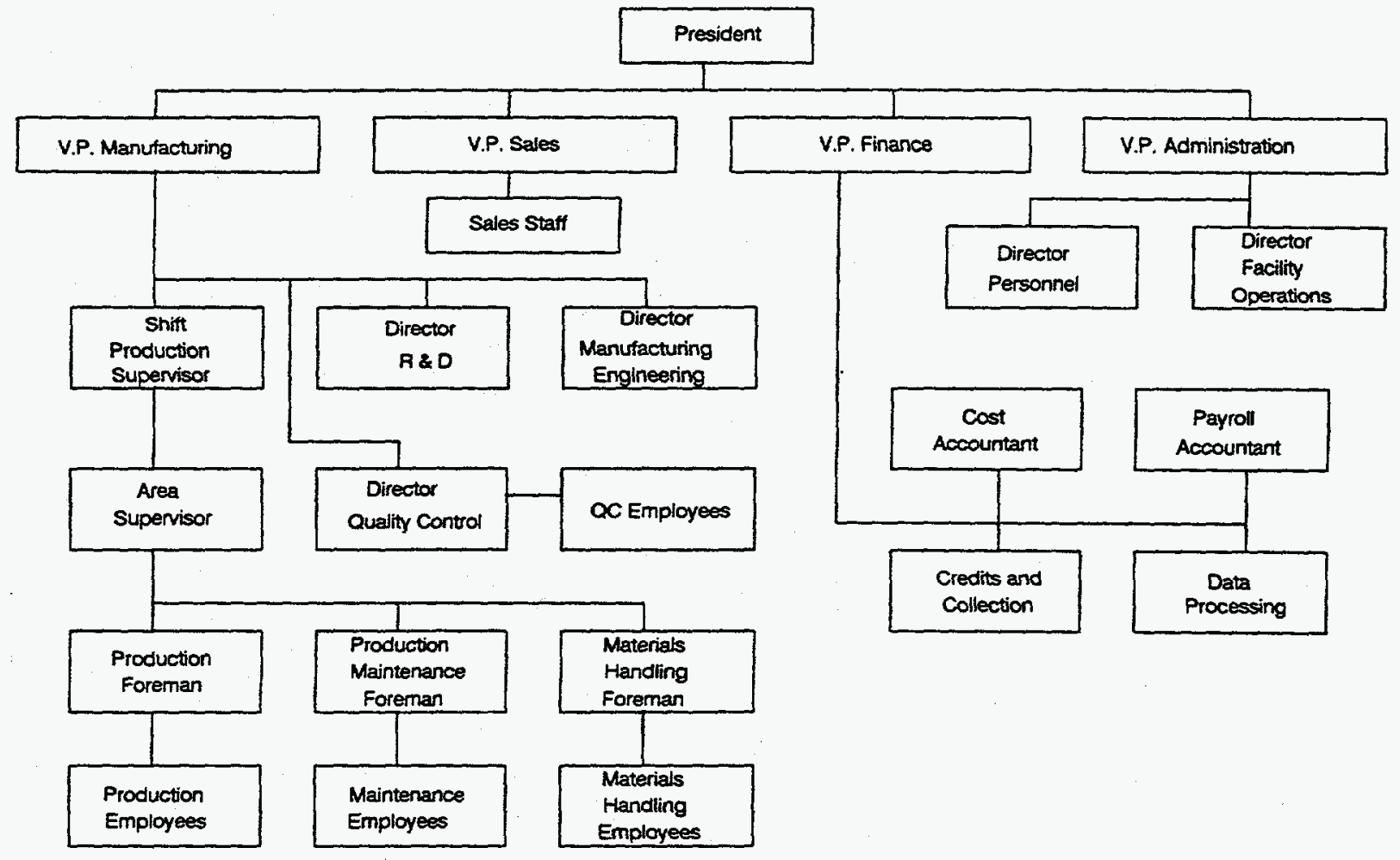

Figure 1. Corporate Organizational Structure.

Cost Center A

Cost Center B

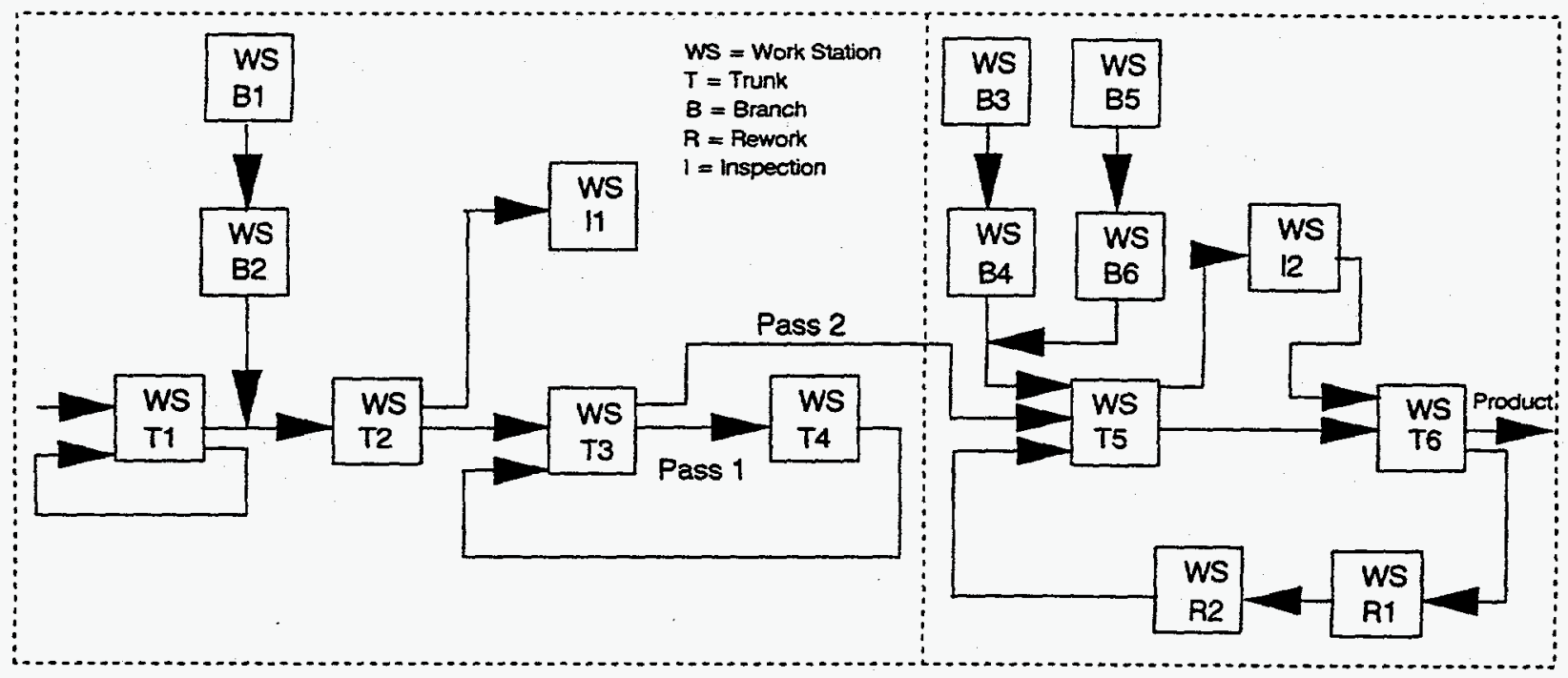

Figure 2. Production Flow Features. 


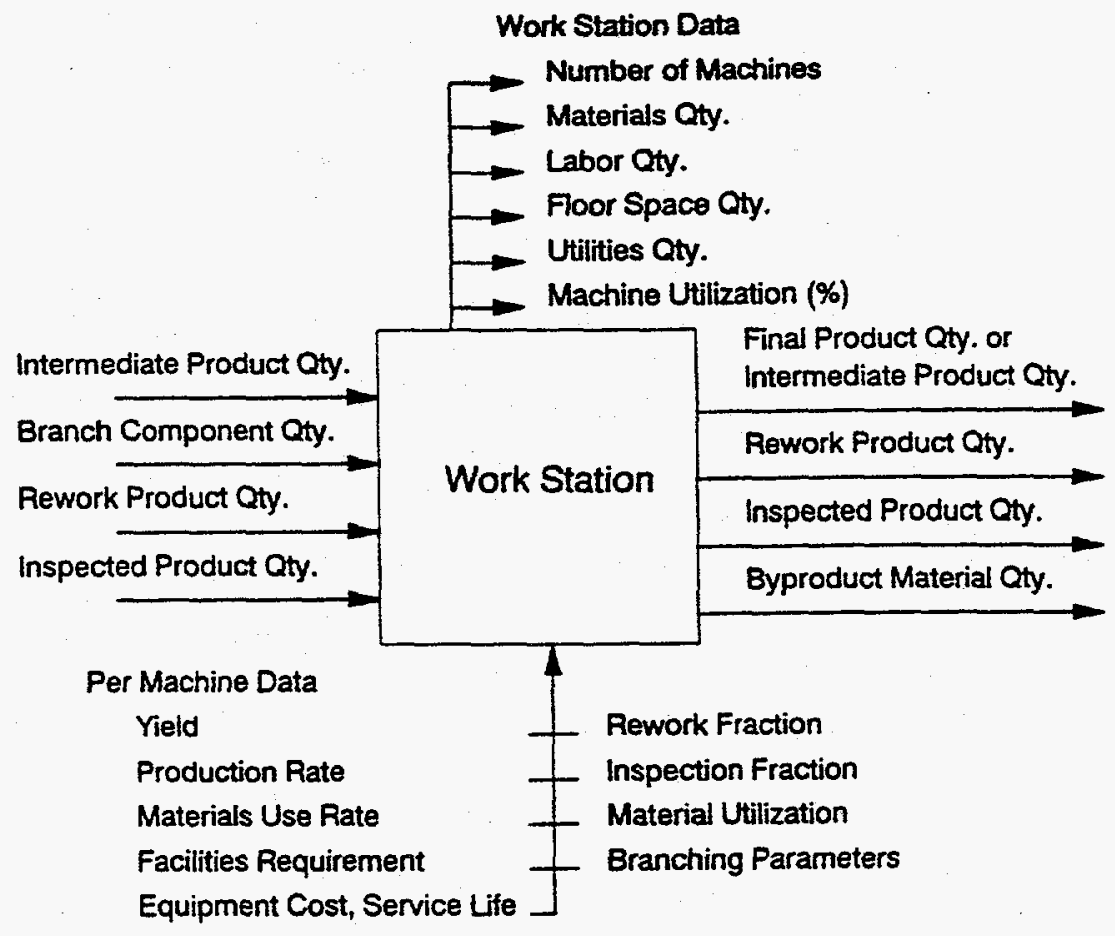

Figure 3. Work Station Data Definition.

\section{Modeling Procedure}

An overview of the STAMPP modeling procedure is shown in Figure 4. In order to use the software, it is first necessary to have a concept of the product design and the necessary manufacturing operations. Those manufacturing operations must be translated into specifications of manufacturing equipment in terms of specified input data items or categories of data items, many of which were defined in Figure 3. All input to the model is carried out interactively by response to queries on the screen or by filling in tables. Selection of output data formats is also interactive and menu-driven. A brief explanation of the blocks in Figure 4 is provided in the following paragraphs.

Production Routing. A list of trunk work stations by user-selected name in the order of product flow and ending with the final product is provided by the user. For trunk stations having branches, a sequence of branch work stations is also input, followed by rework sequences and inspection sequences where appropriate.

Cost Catalog. All job titles required by the organizational structure in Figure 1 are listed in a table called the Cost Catalog. The user supplies annual salaries for these. The job titles for the production area (i.e., those categories defined in Figure 1) for a particular simulation can 


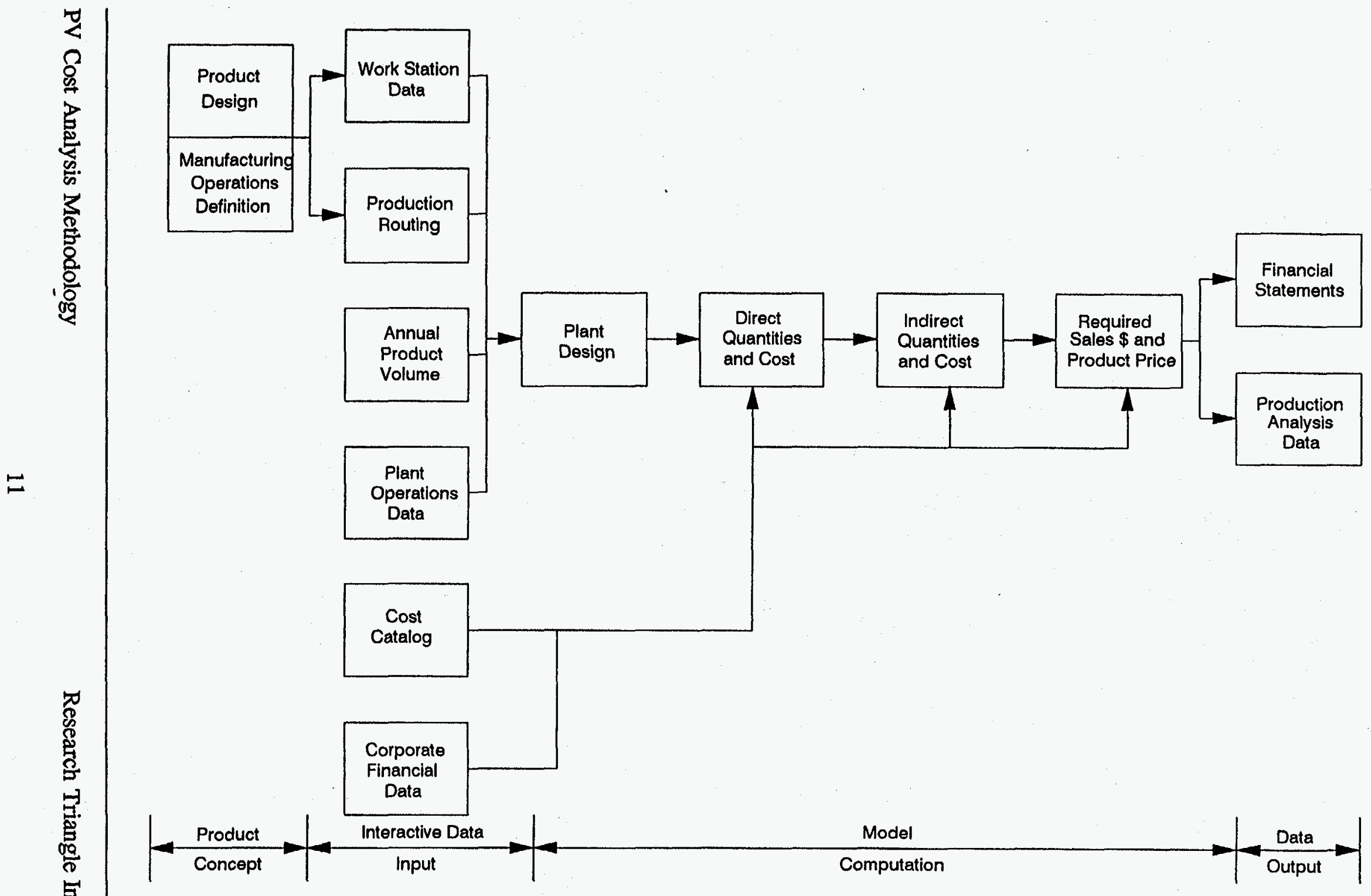

Figure 4. STAMPP Modeling Overview 
be defined by the user by adding them to the cost catalog along with their annual salary or wages. For example, the production employees category might include up to 15 different jobtitles representing different skills or skill levels and different pay rates. The user also lists, by name, in the cost catalog all material and utilities items required in the production of the product along with their unit costs.

Work station Data. Figure 3 defines the most important work station data items or categories. Specific materials, facilities, or job titles particular to each work station are selected by the user from the master list in the Cost Catalog.

Plant Operations Data. The following input data allow the model to scale the production equipment complement based on the available operating time and the production capability of each type of equipment. The data also allow the model to determine the total number of employees in each job position and subsequently the total labor costs.

Number of shifts per working day

Operating hours per shift (hours)

Operating days per week (days)

Operating weeks per year (weeks)

Closed weekdays per fiscal year (days)

Working hours per person per shift (hours)

Working days per working week (days)

Working weeks per fiscal year (weeks)

Paid holidays per operating year (days)

Paid vacation days per operating year (days)

Paid sick days per operating year (days)

Second-shift wage multiplier (fraction)

Third-shift wage multiplier (fraction)

Corporate Financial Data. The input data items below allow STAMPP to determine labor overhead costs for the corporate entity being modeled and to account for the cost of money. The data also allow determination of earnings required by the shareholders, as well as certain other costs such as taxes and insurance.

Base year

Required return on equity (fraction)

Debt to equity ratio (fraction)

Bond interest rate (fraction)

Marketable securities interest rate (fraction)

Combined Federal/State income tax rate (fraction)

Property tax rate (fraction)

Property insurance rate (fraction)

FICA salary cutoff level (\$/yr)

FICA rate (fraction)

Unemployment insurance (\$/employee/yr) 
Hospitalization and other medical

benefits (\$/employee/month)

Fringe benefits (fraction)

Pensions (fraction)

STAMPP will simulate operation over a user-specified period of years. The base year defines the first year of operations. All wage rates and unit costs for materials and equipment are escalated over the period according to annual user-specified escalation (inflation) rates. Depreciation of equipment and facilities is done according to a user-selected method. Equipment and facilities are replaced at the end of their service life.

Annual product volume. The final product volume on an annual basis produced by the corporate entity. This figure is used by the model to scale all of the direct manufacturing and indirect support used by the firm in accordance with the manufacturing input data and the organizational span-of-control rules built into the model.

After data input has been completed the STAMPP model carries out the plant design step. As alluded to previously, a steady-state process balance is performed starting at the end of the process which defines the quantity of intermediate product at the input to every work station, using the data supplied for yields, production rates, rework and inspection at every work station. The primary result is the number of individual machines (or equipment) at every work station. Since labor, materials, and facilities are defined on a per-machine basis, the total quantities of those can then be determined in the "direct quantities and cost" step. Based on unit costs in the Cost Catalog, the individual direct costs for all categories at each work station are determined.

Having determined the employment in the direct manufacturing operations, it is then added to the fixed management positions. The total is used to determine the remaining administrative support staff employment using a set of rules in the model. The total employment is thus determined, and facilities, utilities and other costs to support them are then determined in the "indirect quantities and costs" step.

With direct and indirect costs determined for all operations of the corporate entity, STAMPP proceeds to determine the annual dollar sales required to support the entity. The unit product price required is calculated as sales dollars divided by annual product volume. In order to determine sales volume, STAMPP, in essence, constructs a corporate income statement beginning with required earnings defined as a return on equity investment. Equity is determined by the necessary investment in production equipment and support facilities as previously computed based on the specified annual product volume and machine production capabilities. A capitalization structure is determined by the debt/equity ratio. All equipment and facilities are depreciated over their specified service life by user-selected depreciation rules. Cash generated is assumed to be invested in short-term securities. Interest earned or paid, taxes, and all operating expenses are accounted by accepted procedures to determine the annual sales. The resulting sales required, along with the intermediate calculations, are displayed in the form of 
an annual income statement. STAMPP also produces a corporate balance sheet, cost-of-goodsmanufactured report and a sources-and-uses-of-funds report.

The financial statements are available from the video terminal or in hard copy if a printer is available. In addition, an executive summary report provides selected data identifying a particular simulation case and aggregated price-component information that is useful in suggesting which of the more detailed reports should be examined. These reports include

Input Data
Labor Utilization
Miscellaneous Parameters
HVAC Parameters
Financial Parameters
Inflation Rate Table
Cost Catalog
Work Station Input Data

Output Data

Process Equipment Summary

Manufacturing Direct Labor Summary

Manufacturing Indirect Labor Summary

Manufacturing Facilities Summary

Manufacturing Direct Utilities Summary

Manufacturing Indirect Utilities Summary

Manufacturing Direct Commodities Summary

Manufacturing Byproduct Summary

Manufacturing Miscellaneous Summary

Nonmanufacturing Labor Summary

Nonmanufacturing Facilities Summary

Nonmanufacturing Utilities Summary

Nonmanufacturing Miscellaneous Summary

\section{Application of Criteria}

Quantitative criteria for ranking the Phase 2A proposals were defined previously in the Quantitative Criteria section. Before defining a specific procedure for applying these criteria to Phase 2A proposals, some additional discussion of the weighting to be given to the criteria is in order. In Figure 5, an example of the relationship of a breakeven module price (MAC) in $\$ / \mathrm{m}^{2}$ to system and module efficiency is plotted as a solid line, all other parameters being held constant. The values of the parameters used in the plot are similar to those appropriate to the utility market. The relationship for MAC versus efficiency can be plotted for any market, however, if the parameters for the market can be defined. The relationship in Figure 5 is actually based on system efficiency. However, the proposers will specify module efficiency. An appropriate relationship between the two efficiencies needs to be defined in order to rank 


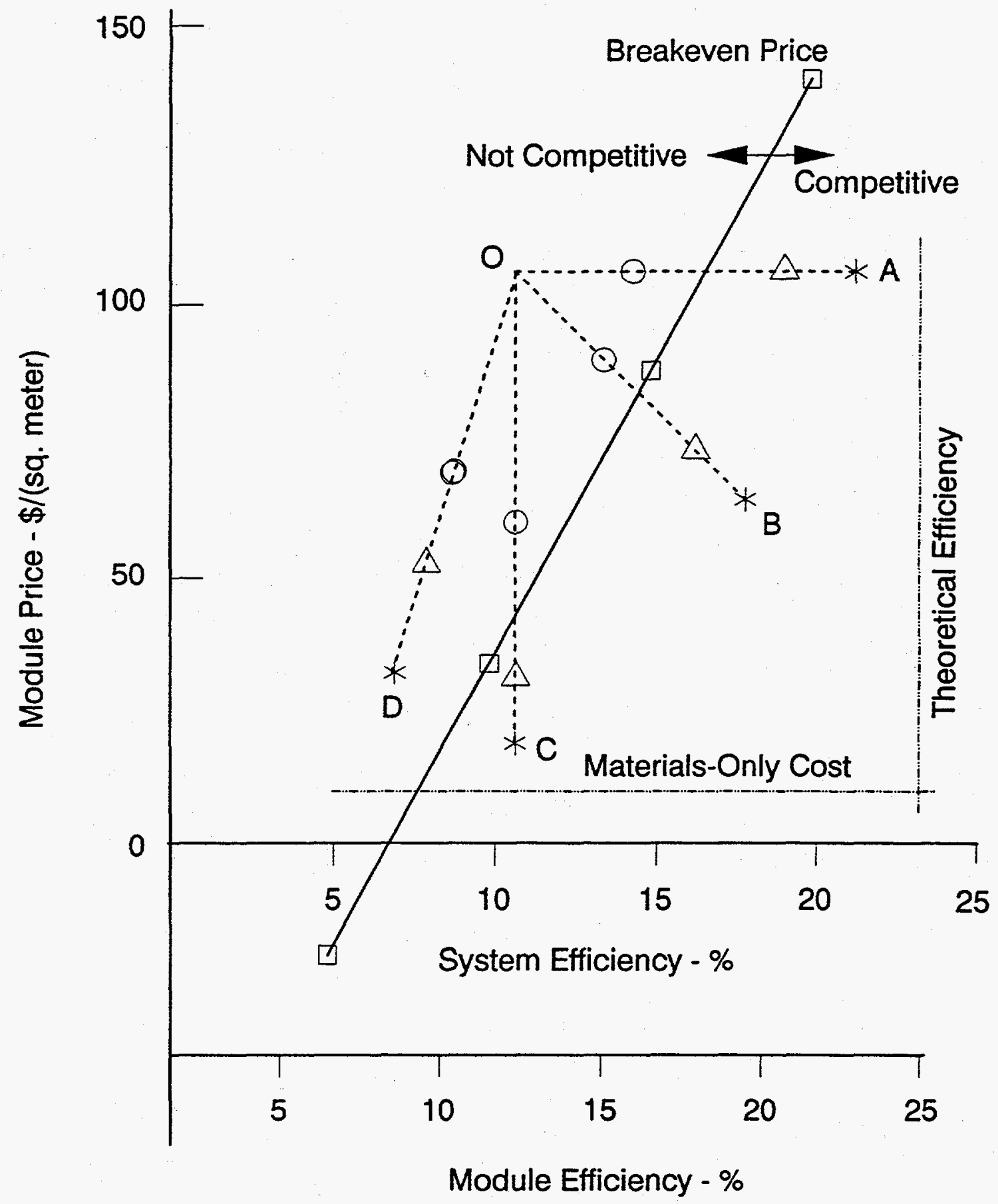

Figure 5. Example PV Cost Analysis Criteria Application 
proposals, especially if there is any likelihood that the relationship would be different for the different proposals.

The usefulness of Figure 5 lies in visualizing the relationships between the various criteria: module price in $\$ / \mathrm{m}^{2}$, which is the measure that directly reflects the productivity of the manufacturing process; the efficiency of the module, which is a measure of the design of the module and to some extent the manufacturing process; and the breakeven price that defines the market entry point. In Figure 5, any combination of module price and efficiency to the left and above the breakeven price curve is not competitive in the market, and any combination to the right and below is competitive. This illustrates that there is no single combination of price in $\$ / \mathrm{m}^{2}$ and efficiency that defines whether the module is competitive, but rather there is some region that defines competitiveness or lack thereof. It is true, however, that for each module technology there are characteristics of design, cell physics and manufacturing processes that will define a particular characteristic region. The breakeven line, which is defined by parameters exogenous to the module technology, defines the boundary between the competitive and noncompetitive regions.

The dashed lines in Figure 5 represent paths that might be followed by a module which is not competitive in a given market at the start of the Phase $2 \mathrm{~A}$ effort, the point $\mathrm{O}$ being the starting point. Path OC represents a proposal that is aimed strictly at reducing the manufacturing cost of the module with no change in efficiency. Path OA represents a proposal aimed at improving efficiency at the same module price, and $\mathrm{OB}$ represents some reduction in price and improvement in efficiency at the same time. The line OD represents a case which is quite likely in practice where there is a reduction in both price and efficiency. It suggests how difficult it may be to achieve breakeven with efforts to reduce manufacturing costs if efficiency is degraded at the same time. Price and efficiency achieved by the Phase $2 \mathrm{~A}$ effort are both important. The relative value of price and efficiency in achieving breakeven depend on the slope of the breakeven price line, and that slope depends on the parameter values in the MAC relationship that are a function of both the market and the module technology. The points denoted by circles and diamonds on the technology paths represent possible final accomplishments of the Phase $2 \mathrm{~A}$ effort, and these may exceed or fall short of breakeven.

The asterisks in Figure 5 represent members of the set of points defining the ultimate price/efficiency region possible with a given technology. While such a region is not precise for any technology, theory and experience (where it exists) can provide a reasonable definition of such a region. As illustrated in Figure 5, this region of ultimate price/efficiency for a given technology is not necessarily entirely in the competitive zone (or even in it at all) for a given market. It may be competitive for some values of price/efficiency and not for others. For example, single junction a:Si is generally conceded not to be able to achieve a high enough stable efficiency to compete in the utility market even though it may have a potentially very low module price. It is important to be aware of the combination of price efficiency values that can ultimately be achieved in relation to the target market breakeven when ranking proposed Phase $2 \mathrm{~A}$ efforts. A module technology that has little or no potential for achieving breakeven would 
be ranked lower than one with that potential, regardless of relative progress proposed for Phase $2 \mathrm{~A}$.

There are two factors that can help define the limits of the ultimate price/efficiency region that are technology specific. First, there are theoretical limits to efficiency under stated conditions that bound the region to the right, as noted in Figure 5. Second, the materials cost incorporated in a module bounds the region at the bottom. These limits may be difficult to establish and arguable as their magnitude in a given case, but establishing them would be helpful in ranking proposals.

The final ranking must be based on evaluation of both the quantitative criteria and qualitative factors. In this section, a procedure for applying the quantitative criteria is defined, keeping in mind the ideas suggested by Figure 5. It consists of three steps:

Step 1. Prepare a breakeven module cost $\left(\$ / \mathrm{m}^{2}\right)$ versus efficiency diagram analogous to Figure 5 for each proposed module.

a. Select the PV market to be used as basis of comparison (electric utility market is suggested.

b. Define the parameter values in the MAC/efficiency relationship for the selected market and module technology.

c.Draw the breakeven cost diagram(s) to a common scale for all technologies to facilitate ranking.

d. Define the region (or line) of ultimate price/efficiency for each module technology on the appropriate diagram.

Step 2. Determine the achievable module price $\left(\$ / \mathrm{m}^{2}\right)$ for each proposed module, both at the inception and at the end of Phase 2A. Use the STAMPP software if sufficient data are available. If not, the cost components defined by STAMPP and the general cost accounting methodology in STAMPP will serve as guidelines to estimate the module prices in a uniform manner.

Step 3. Rank the proposals according to the relationship between the proposed price efficiency point and the breakeven line illustrated by Figure 5. There are two cases:

a. Price/efficiency is in the competitive region. Rank in order of the shortest distance from the proposed end-point to the breakeven line, with longest distance having highest rank. 
b. Price efficiency is not in the competitive region. Rank in inverse order of the shortest distance from the end-point to the breakeven line, but below the lowest ranking module in the competitive region.

Each step is further defined in the following paragraphs.

Step 1. Breakeven module cost.

The breakeven module cost, MAC, versus system efficiency can be calculated from the relationship previously given. Calculation of MAC requires selection of values for the defined parameters, some of which are market-specific and some of which are module-specific. The fact that some parameters are module-specific, or at least technology-specific, means that the $\mathrm{MAC}$ /efficiency line is proposer- or technology-specific. The parameters are discussed here individually to further define them and their relationship to the methodology.

EC (levelized energy cost). This is a market-specific value representing a target cost in $\$ / \mathbf{k W h}$ for PV-produced electric energy.

LCC (fixed charge rate). A market-specific parameter appropriate to the owner of the PV system; levelizes the capital investment over the system life. Assumes all proposed systems have the same life.

CF (PV plant capacity factor). A fraction that converts the peak output of the PV system to annual energy. CF is different for flat plate, fixed or tracking, and concentrator systems. A specific site can be chosen as representative or multiple rankings performed.

INDC (indirect cost multiplier). A multiplier that accounts for the erection costs of the PV system. It may vary depending on whether the system is flat plate (tracking or fixed) or concentrator.

$\mathrm{I}_{\mathrm{p}}$ (peak insolation, $\mathrm{kW} / \mathrm{m}^{2}$ ). Value depends on site and whether the PV system is flat plate or concentrator. Comments for CF apply here.

$\eta_{\mathbf{s}}$ (system efficiency). Overall conversion efficiency of sunlight to electricity for the system. A conversion between system and module efficiency should be chosen based on system type and the proposers specification of anticipated efficiency at a stated temperature condition (junction temperature and ambient temperature.)

BAC (balance of system area costs, $\$ / \mathrm{m}^{2}$ ). Capital costs of all components of the system except the modules whose quantity depends on the physical area of the array, such as site preparation, support structures and wiring. The value of BAC may vary between with module type and tracking method if the proposed module design requires specific support/tracking considerations. 
BPC (balance of system power costs, $\$ / W_{p}$ ). Capital costs of all components of the system whose cost is proportional to the design power capacity, such as the power conversion equipment and substation equipment. A common value for BPC can be chosen.

$\mathrm{L}$ (levelizing factor for recurring O\&M costs). A common value can be chosen assuming the life of all systems is the same.

OM (annual operating and maintenance costs, $\$ / \mathrm{m}^{2}$ ). A value for each system type, fixed flat plate, tracking flat plate, and concentrator, can be chosen if desired, or a common value can be used.

In the above discussion of the parameters, several of the parameters are differentiated according to system or module type, which would result in different breakeven price lines for different modules. If the nature of the Phase 2A proposals is such that such differentiation is not useful or meaningful in the proposal ranking process, either because the ranking does not need that level of specificity to accomplish the ranking or because the data to accomplish it is not available, then values common to all modules can be used.

Step 2. Achievable module price.

The preferred method for determining the achievable module price at the start and end of the proposed Phase 2A activity is to utilize the STAMPP software previously described, which provides a required module price under a defined manufacturing situation. Some modules from given manufacturers may be available for sale at this time and have a market price established given current manufacturing facilities and market size. This market price could be used to establish a current price baseline. However, the interest of the PVMat program is in ranking the process improvements in processes that could satisfy a measurable penetration into the demand for electricity from the grid. Use of the STAMPP software allows the computation of a price that is consistent with the process definition at a product volume consistent with the potential market volume. The PVMaT project should select a product volume, in terms of rated energy capacity $\left(\mathrm{MW}_{\mathrm{p}} / \mathrm{yr}\right)$, at which to evaluate the processes. So long as the value is sufficient to achieve available economy of scale in manufacturing, the production volume is not critical. Use of the STAMPP software also allows determination of the module price under consistent processing and financial parameters for both baseline and improved processes. That is, the effect on price of the proposed manufacturing process developments can be shown with a uniform methodology.

It is not known at this time what level of process descriptive information will be available from the various proposers for calculating prices of modules. The STAMPP software is capable of handling a process definition at varying levels of aggregation. Ideally, the process is defined at in terms of a work station for each major process operation, which usually corresponds to a specific type of equipment. Process operations and associated equipment can be aggregated together in STAMPP in a less detailed process definition, but the confidence in the resultant 
price is lessened and the basis for price reductions becomes less clear as the aggregation increases. However, used at almost any level of process aggregation the software imposes a discipline on the components of cost that should be included in the achievable price and exposes inconsistencies in that data between proposers. The Characterization Parameters define the data required for STAMPP to calculate these prices.

Step 3. Quantitative ranking.

The ranking process described above requires little amplification insofar as ranking on a quantitative basis is concerned. It should be reiterated that the breakeven price/efficiency lines may be different for each module process proposed due to the balance-of-system costs being different for different designs (assuming that such differentiation is needed to differentiate the rankings). The emphasis in the quantitative ranking is on how close to, or how much in excess of, breakeven the proposed manufacturing process improvements will bring the achievable module prices. In the final analysis, market penetration is the most important achievement and the one on which ranking should be based. This ranking provides no credit for the relative progress in module price reduction that may be proposed (i.e., the reduction in starting and ending price), whether or not the ending price achieves or exceeds breakeven. Certainly this relative progress may be important, but it must be viewed in terms of other considerations. For example, relative progress may be large in a given case, but the end-point price may fall considerably short of breakeven. For some module(s), the consideration of the ultimate price/efficiency region may show that they are unlikely to ever achieve breakeven. For others, the same considerations may show much potential for exceeding the current definition of breakeven. Relative progress has little value in such circumstances. Conversely, where the endpoint price is short of breakeven, if a potential for exceeding it can be inferred from the relationship between breakeven and ultimate price/efficiency regions, then relative progress for such a module technology would be valuable. To summarize the considerations of relative progress, its value must be seen in light of the ultimate potential of the particular module/process and the closeness of the end-point price/efficiency to the breakeven line. Relative progress of itself does not have a measurable value that contributes directly to the ranking.

The region (or line) of ultimate price/efficiency points for a technology is also not directly reflected in the ranking. Rather, it aids in interpreting or constraining the ranking based on breakeven considerations. For modules in the competitive region, comparison of the ultimate price/efficiency points serves to suggest which one may be the eventual winner in a competitive environment, but the state-of-the-art in large-scale manufacture of PV systems is not sufficiently developed to forecast this far into the future. Thus, the ultimate price/efficiency of modules is used here only to possibly exclude some module/processes or to establish potential for those where prior development has been limited.

\section{Proposal Selection Issues}

This PV Cost Analysis Methodology is not strictly concerned with the final selection of Phase 2A proposals for funding. However, the process of defining this methodology to provide 
a quantitative approach to ranking the proposals suggests some issues relating to the ranking process that bear on the proposal selection that should be discussed. Assuming that the proposals can be ranked quantitatively, the issue remains as to how many proposals should be funded and which proposals should be funded. The answers to those questions lie partly in the prudent allocation of the available funding and partly in the interpretation of the rankings. As to allocation of resources, the variety of cell/module technologies under consideration is large and the uncertainty associated with both the rankings on the one hand and with technology evolution on the other makes it imprudent not to support at some level several proposals (say 5 to 10 , assuming that many are attractive based on rankings and other factors.) Funding too many spreads the available funds to thinly to make an impact, but funding too few increases the risk that the program impact will be reduced because the ones funded fall short of projected results. Care should be taken not to allow the rankings to lead to a high risk mix of funded proposals.

Assuming then that it is wise to fund several proposals, what do the rankings say about the selection? Should the proposals be funded simple in numerical order of their ranking? Or should additional considerations be applied in the selection process? In this discussion, it is a given that no module/process technology is currently competitive in the utility market; that is, all points labeled " $O$ " in Figure 5 are in the noncompetitive region. There are two classes of ranked proposals: those whose end-point is projected to exceed the breakeven line and those that fall short of it. There are sure to be some of the latter and there may or may not be some of the former. To some extent, where a given proposed effort falls with respect to the breakeven point depends on the accuracy of the process descriptive data used to define the end-point. STAMPP, or an approximate use of the its methodology, will provide end-points for ranking that reflect the input data. These will be optimistic or pessimistic depending on the input data. A good example is the data defining throughput in the more costly steps of a process. A number of previous studies have used very optimistic numbers and the resultant estimates of module price are optimistically low. It is important to assess the likelihood of the proposed processes achieving the specified performance.

In the earlier section on Quantitative Criteria, several considerations were restated relating to the likelihood that Phase $2 \mathrm{~A}$ proposed manufacturing process improvements would succeed and what would be their impact on price and efficiency. These relate to the quality of the effort proposed, the adequacy of the requested funding, the amount of funding to be devoted to it by the proposer, and the commitment of the proposer to the PV industry. The likelihood of success is not addressed by the quantitative ranking except to the extent that closeness of approach of the end-point price/efficiency to the breakeven signifies likelihood. The other likelihood factors must be assessed as additional qualitative or judgmental criteria by the reviewers. These qualitative factors are quite important, and hopefully they will be more meaningful when assessed against a background of the quantitative ranking.

There are some other considerations for the two classes of rankings that are important. To begin with, a ranking based on the magnitude of the distance between the achievable module price/efficiency and breakeven line suggests that the proposal selection should emphasize funding 
those that fall farthest into the competitive region. However, given no segmentation of the market represented by the breakeven line, and assuming no uncertainty in the breakeven line or rankings, there is no reason to use funding to push a module technology beyond the breakeven line. Any technology on the line will penetrate the market. Thus, the distance into the competitive region indicated by the ranking of a technology is more a measure of confidence that the projected price/efficiency point used for ranking will be achieved than it is a goal of the funding. Depending on the projected price/efficiency points of the various technologies, it may be wise to fund more proposals at lower funding for each in order to help a larger number cross the breakeven line by a small amount rather than to have a smaller number cross it by a large amount. Of course there is not a linear relationship in the amount of funding provided and the size of the process improvement, and this complicates the situation further. The assessment of the confidence in having some technologies become competitive versus the number that become competitive is not addressed by the ranking methodology, and is to some extent dependent on what is proposed for Phase 2A and what the projected end-points turn out to be. There are other confidence (or likelihood) factors, primarily relating to the commitment of the proposer and the quality of the proposed effort that will also influence the selection. All of these points argue for carefully considered application of the rankings.

Analogous discussion to the above can be developed for the proposals that are projected to be noncompetitive at their end-points. It is natural to want to fund those whose end-points are closest to the breakeven line. However, the ultimate potential of these technologies must also be taken into account. If a proposed technology is projected to come close to the line, but its competitive region is small, then it may be poorer choice than a technology that is not quite so close to the line but exhibits a larger competitive region. The same arguments about the number of proposals funded in terms of the risk of choosing too few or too restricted a mix of technologies hold for noncompetitive technologies as well as competitive ones.

It is intended that these comments on applying a ranking that is quantitative will aid in the thinking about what might be termed the objective function for proposal selection. Whether a quantitative objective function can or should be defined is beyond the scope of this methodology, but there will no doubt be a general set of policy guidelines for selection. The use of STAMPP or a STAMPP-based procedure for defining projected proposal accomplishments in a quantitative manner and ranking them can be a valuable component of the selection process if handled with the issues just described in mind.

\section{References}

1. Roger W. Taylor, Photovoltaic Systems Assessment: An Integrated Perspective, AP-3176-SR, Electric Power Research Institute, September 1983. 


\begin{tabular}{|c|c|c|c|}
\hline $\begin{array}{l}\text { Document Control } \\
\text { Page }\end{array}$ & $\begin{array}{l}\text { 1. NREL Report No. } \\
\text { NREL/TP-411-5017 }\end{array}$ & $\begin{array}{l}\text { 2. NTIS Accession No. } \\
\text { DE92016441 }\end{array}$ & 3. Recipient's Accession No. \\
\hline \multirow{2}{*}{\multicolumn{3}{|c|}{$\begin{array}{l}\text { 4. Title and Subtitle } \\
\text { Cost Analysis Methodology }\end{array}$}} & $\begin{array}{l}\text { 5. Publication Date } \\
\text { September } 1992\end{array}$ \\
\hline & & & 6. \\
\hline \multicolumn{3}{|l|}{$\begin{array}{l}\text { 7. Author(s) } \\
\text { Richard A. Whisnant }\end{array}$} & 8. Performing Organization Rept. No. \\
\hline \multirow{2}{*}{\multicolumn{3}{|c|}{$\begin{array}{l}\text { 9. Performing Organization Name and Address } \\
\text { Research Triangle Institute } \\
\text { Research Triangle Park, North Carolina } 27702\end{array}$}} & $\begin{array}{l}\text { 10. Project/TaskWWork Unit No. } \\
\text { PV250101 }\end{array}$ \\
\hline & & & $\begin{array}{l}\text { 11. Contract (C) or Grant (G) No. } \\
\text { (C) XR-1-11039-1 } \\
\text { (G) }\end{array}$ \\
\hline \multirow{2}{*}{\multicolumn{3}{|c|}{$\begin{array}{l}\text { 12. Sponsoring Organization Name and Address } \\
\text { National Renewable Energy Laboratory } \\
1617 \text { Cole Blvd. } \\
\text { Golden, CO } 80401-3393\end{array}$}} & $\begin{array}{l}\text { 13. Type of Report \& Period Covered } \\
\text { Technical Report } \\
11 \text { March } 1991 \text { - } 11 \text { November } 1991\end{array}$ \\
\hline & & & 14. \\
\hline \multicolumn{4}{|c|}{$\begin{array}{l}\text { 15. Supplementary Notes } \\
\text { NREL technical monitor: R.L. Mitchell }\end{array}$} \\
\hline \multicolumn{4}{|c|}{$\begin{array}{l}\text { This report describes work done under Phase } 1 \text { of the Photovoltaic Manufacturing Technology (PVMaT) Project. PVMaT is a } \\
\text { five-year project to support the translation of research and development in PV technology into the marketplace. PVMaT, } \\
\text { conceived as a DOE/industry partnership, seeks to advanced PV manufacturing technologies, reduce PV module production } \\
\text { costs, increase module performance, and expand U.S. commercial production capacities. Under PVMaT, manufacturers will } \\
\text { propose specific manufacturing process improvements that may contribute to the goals of the project, which is to lessen the } \\
\text { cost, thus hastening entry into the larger scale, grid-connected applications. Phase } 1 \text { of the PVMaT project is to identify } \\
\text { obstacles and problems associated with manufacturing processes. This report describes the cost analysis methodology required } \\
\text { under Phase } 1 \text { that will allow subcontractors to be ranked and evaluated during Phase } 2 \text {. }\end{array}$} \\
\hline \multicolumn{4}{|c|}{$\begin{array}{l}\text { 17. Document Analysis } \\
\text { a. Descriptors } \\
\text { cost analysis ; manufacturing ; photovoltaics ; solar cells } \\
\text { b. Identifiers/Open-Ended Terms }\end{array}$} \\
\hline \multicolumn{4}{|l|}{$\begin{array}{l}\text { c. UC Categories } \\
270\end{array}$} \\
\hline \multirow{2}{*}{\multicolumn{2}{|c|}{$\begin{array}{l}\text { 18. Availability Statement } \\
\text { National Technical Information Service } \\
\text { U.S. Department of Commerce } \\
\text { 5285 Port Royal Road } \\
\text { Springfield, VA } 22161\end{array}$}} & & $\begin{array}{l}\text { 19. No. of Pages } \\
27\end{array}$ \\
\hline & & & $\begin{array}{l}\text { 20. Price } \\
\text { A03 }\end{array}$ \\
\hline
\end{tabular}

Form No. 0069E (6-30-87) 